\title{
A Indústria de Confecção do Vestuário de Pato Branco: Aspectos de Gestão, Design, Caracterização de Matérias- Primas e Geração de Resíduos Têxteis
}

The Clothing Industry of Pato Branco: Aspects of Management, Design, Characterization of Raw Materials and Generation of Textile Waste

Andréia Mesacasa Mestre, Instituto Federal do Rio Grande do Sul andreiamesacasa@hotmail.com

Mário Antônio Alves da Cunha Doutor, Universidade Tecnológica Federal do Paraná mcunha@utfpr.edu.br 


\title{
A Indústria de Confecção do Vestuário de Pato Branco: Aspectos de Gestão, Design, Caracterização de Matérias-Primas e Geração de Resíduos Têxteis
}

The Clothing Industry of Pato Branco: Aspects of Management, Design, Characterization of Raw Materials and Generation of Textile Waste

Andréia Mesacasa, Mário Antônio Alves da Cunha

\section{Resumo}

Esta pesquisa possui como foco a indústria de confecção do vestuário no município de Pato branco, evidenciando aspectos relativos à gestão, design, caracterização de matérias-primas e geração de resíduos. No presente estudo foi realizado um diagnóstico junto às empresas, com o intuito de obter informações referentes aos perfis das mesmas, destacando as formas de gestão, design e desenvolvimento de produto, matérias-primas utilizadas e geração de resíduos têxteis. Tais empresas caracterizam-se como empreendimentos de micro e pequeno porte, atuando em diferentes segmentos de mercado, com forte tendência a produção de uniformes profissionais. Em consequência disso, grande parte dos resíduos gerados é constituída por retalhos de malha. Neste sentido, uma alternativa para o reaproveitamento destes resíduos poderia contribuir tanto do ponto de vista ambiental por meio de um melhor direcionamento destes, como economicamente, uma vez que poderiam ser voltados para a produção de produtos de maior valor agregado.

Palavras-chave: Indústria, Vestuário, Resíduos têxteis

\begin{abstract}
This research focuses on the clothing industry in the Pato Branco city, highlighting aspects related to management, design, characterization of raw materials and generation of waste. In the present study, a diagnosis was made with the companies, with the purpose of obtaining information on their profiles, highlighting the management, design and development of the product, raw materials used and generation of textile waste. These companies are characterized as micro and small enterprises, operating in different market segments, with a strong tendency to produce professional uniforms. As a result, much of the waste generated is knitted scraps. In this sense, an alternative for the reuse of these wastes could contribute from the environmental point of view by means of a better targeting of these, as well as economically, since they could be directed towards the production of products of greater added value.
\end{abstract}

Keywords: Industry, Clothing, Textile waste 


\section{Introdução}

A região Sudoeste do Paraná apresenta potencial para o mercado de trabalho na área de design de moda e vestuário, pela sua extensão na indústria, no comércio e na prestação de serviços. Segundo dados do SINVESPAR (2008), existem aproximadamente 276 empresas no ramo do vestuário que abrangem 42 municípios do Sudoeste do Paraná, sendo que 21 empresas estão localizadas no município de Pato Branco. A maior parte destas empresas atua diretamente com o processo de produção de peças do vestuário, salvo algumas destinadas a serviços especializados como estamparia, bordado e lavanderia. Os segmentos mais trabalhados no município de Pato Branco são os de uniformes escolares e profissionais, modinha feminina e ateliês que confeccionam peças sob medida.

O processo de produção do vestuário envolve uma série de etapas, que vão desde a criação até a comercialização das peças, englobando as seguintes operações: pesquisa, criação, modelagem, prototipia, enfesto, encaixe, risco, corte, costura, acabamento, embalagem e comercialização. Dentre estas operações, em especial na etapa do corte há um percentual de matéria-prima que será descartada em virtude da modelagem da peça do vestuário ser anatômica, e esta, por sua vez, não obter um encaixe perfeito com aproveitamento total do tecido. Além disso, o fator sazonalidade produz um montante significativo de resíduos têxteis, quais sejam sobras de tecidos em suas diferentes composições (naturais, artificiais ou sintéticas) bem como aviamentos (componentes como zíperes, linhas, botões). Aliado a estes fatos estão os processos de beneficiamentos que incluem os serviços de serigrafia (estamparia) e tinturaria (tingimento) responsáveis por gerar efluentes nocivos ao meio ambiente.

Assim, vislumbrando o cenário de desenvolvimento da região Sudoeste do Paraná e levando em consideração a atual conjuntura social e ecológica que permeia o universo dos bens de consumo intermediados pelo processo de design, buscou-se através do presente trabalho avaliar aspectos de gestão, design bem como caracterizar as matérias-primas e resíduos têxteis gerados durante o processo produtivo da indústria de confecção do município de Pato Branco. 


\section{Evolução da indústria do vestuário no sudoeste do Paraná}

A indústria de confecção é um dos setores industriais mais antigos do Brasil. De acordo com Furtado (1988), o setor têxtil e a indústria de confecção foram os precursores da industrialização brasileira e estiveram na liderança deste processo no país, com grande importância no desenvolvimento econômico, tanto na produção de renda como na geração de emprego.

A região sudoeste paranaense é constituída por 42 municípios predominantemente de pequeno porte, faz fronteira a oeste com a Argentina e ao sul com o Estado de Santa Catarina (SINVESPAR, 2006).

Por exigir pouco nível tecnológico e pequeno investimento de capital, a indústria de confecção foi precursora do processo de industrialização da região e, assim como ocorreu no início da industrialização brasileira, se tornou um dos setores mais importantes para o desenvolvimento econômico da região. Essa indústria iniciou suas atividades no final da década de 1970 e início da década de 1980.

$\mathrm{Na}$ década de 1970 houve mudanças expressivas na estrutura socioeconômica brasileira, na qual fatores como o êxodo rural, e a forte inserção da mulher no mercado de trabalho contribuíram para algumas mudanças neste setor. Neste contexto, a região Sudoeste do Paraná, composta por municípios jovens (entre 10 a 20 anos de emancipação política), população predominante de imigrantes italianos e alemães provenientes das regiões Oeste de Santa Catarina e Serra Gaúcha, iniciou as atividades relacionadas à indústria do vestuário. Esta se deu em virtude da experiência de alfaiates, pessoas que fabricavam roupas masculina sob medida (calças, camisas e paletós) e que nas décadas de 1970 e 1980 viram na atividade a oportunidade de passar a fabricar estes produtos em escala industrial. Dessa forma, estes produtos foram incorporados ao mix de produtos de estabelecimentos comerciais regionais, pertencentes à própria familia ou comercializados por ambulantes em municípios vizinhos (SINVESPAR, 2006).

Apesar das dificuldades que a região apresentava tais como: difícil acesso a outros polos do Estado, poucas rodovias com pavimentação asfáltica, inexistência de fornecedores de matéria prima, de mão-de-obra especializada, de prestadores de serviços, as indústrias surgiam e desenvolviam-se sem estrutura de 
apoio externo, fatores que motivaram a união de empresários no intuito de promover o desenvolvimento do setor através da busca de soluções em conjunto. Nesse cenário está a vinda dos primeiros profissionais de manutenção e conserto de máquinas, os primeiros cursos de formação de operadores de máquinas, a promoção e divulgação do setor com os primeiros eventos regionais, bem como as primeiras viagens a feiras especializadas (SINVESPAR, 2006).

Na década de 1990 devido à abertura econômica, o setor sofreu um processo de reestruturação, impulsionando a abertura de novos negócios neste setor, sobretudo por profissionais que haviam perdido seus empregos por conta da crise que na época se instalou em todo o Brasil.

No final dos anos de 1980 e no decorrer da década de 1990, tornou-se um dos setores industriais com maior importância econômica da região, em termos de geração de emprego e renda. Nos últimos anos, especialmente a partir da década de 1990, a indústria de confecção regional vem crescendo aceleradamente tanto em número de unidades industriais, com um crescimento de 304\% entre 1990 e 2006, quanto em escala de produção e comercialização (SINVESPAR, 2006).

Atualmente o sistema produtivo da indústria da confecção do Sudoeste do Paraná está presente em 27 dos 42 municípios da região, onde se destacam em número de unidades, valor agregado e geração de emprego os municípios de Ampére (6ำ no ranking estadual), Dois Vizinhos (8ํ), Francisco Beltrão (14\%), Santo Antônio do Sudoeste $\left(22^{\circ}\right)$ e Pato Branco $\left(28^{\circ}\right)$. O parque industrial é composto por mais de 276 unidades (vestuário e decoração/inha lar) gerando aproximadamente 5.956 empregos diretos, (IPARDES, 2009).

Dentro deste conjunto, o setor do vestuário possui o segundo maior Valor Adicionado da indústria da transformação e na geração de empregos diretos na região do Sudoeste. A produção de vestuário é estimada em 16 milhões de peças/ano, com predominância para moda masculina (calças, camisas, paletós), jeans e modinha feminina (SINVESPAR, 2006).

Em junho de 1992 foi fundado o Sindicato das Indústrias do Vestuário do Sudoeste do Paraná (SINVESPAR), que tem como missão atuar como representante corporativo da indústria do vestuário da região sudoeste. 
Em 2003, o setor do vestuário, em parceria com diferentes instituições da Região, engajados na proposta de alavancagem do setor, uniram-se em torno da proposta de formar o Polo da Confecção do Sudoeste do Paraná para ser reconhecido pelo Ministério do Desenvolvimento, Indústria e Comércio Exterior (MDIC) através do Programa dos Polos, tornar a indústria de confecção do Sudoeste reconhecida e lançar a marca "Moda Sudoeste Paraná" (SINVESPAR, 2006).

Em 2005, o projeto Polo da Confecção do Sudoeste do Paraná, foi alterado para APL Confecção Moda Sudoeste. O APL Confecção Moda Sudoeste priorizou ações voltadas ao mercado nacional/internacional, gestão e formação de mão-de-obra, finanças e investimentos, meio ambiente, saúde, segurança e cidadania. O APL compreende os seguintes municípios: Ampére, Barracão, Capanema, Chopinzinho, Dois Vizinhos, Francisco Beltrão, Pato Branco, Pranchita, Planalto, Realeza, Salto do Lontra e Santo Antônio do Sudoeste.

Pato Branco é um dos principais centros urbanos da região, com população de 72.370 e taxa de urbanização de 94,09\% (IPARDES, 2011). O mesmo se constitui não apenas como polo de atividade econômica do sudoeste paranaense, mas também um centro urbano de referência regional, possuindo um grau de urbanização acima da média paranaense. Dentro deste contexto, o município destaca-se por ocupar a $3^{\text {a }}$ posição estadual no que se refere ao Índice de Desenvolvimento Humano (IDH), com a média de 0,849.

Conforme dados do TM - RAIS, (apud IPARDES, 2011) em Pato Branco o setor de atividade econômica de indústria têxtil, do vestuário e artefatos de tecidos é composto por 21 estabelecimentos que geram 121 empregos diretos.

Sob este aspecto, o setor industrial de Pato Branco é formado em sua maioria por empresas de micro, pequeno e médio portes, mas em desenvolvimento, com alguns segmentos que sobressaem pela representatividade do número de empresas e de empregos gerados e pela sua dinâmica de mercado. Tais segmentos são: metalúrgico (envolvendo inclusive o complexo da produção de fogões), moveleiro, de confecções, de construção civil, tecnológico e agroindustrial (alimentos). 
Conforme Saquet (2008), o principal motivo de expansão do ramo de confecções na região e em Pato Branco, está atrelado à mão-de-obra barata, predominantemente feminina, como também ao baixo custo para investimentos de capital fixo (maquinários) para se montar uma empresa. Contudo, muitas empresas iniciaram suas atividades e pouco tempo depois entraram em processo de falência. O autor salienta que o principal motivo da falência é a falta de conhecimento na área, o que leva muitos a produzirem roupas de baixa qualidade. Neste sentido, ações promovidas por diferentes segmentos da sociedade, como escolas nos níveis pós-médio e superior, além de prefeituras e outras instituições públicas e privadas, buscam aumentar a qualidade destas empresas, sobretudo através da qualificação profissional dos empresários e de seus funcionários, bem como na participação destes em eventos estaduais e nacionais, o que demonstra avanços rumo ao aumento do nível de qualidade do setor.

\section{Estratégias metodológicas}

O diagnóstico dos aspectos de desenvolvimento, gestão e design das empresas de confecção teve como objetivo a compreensão do fenômeno estudado através da mensuração de diferentes fatores, sendo esses necessários para o delineamento do perfil das empresas. Foram empregados questionários compostos por questões fechadas de múltipla escolha e questões abertas, os quais foram aplicados nas indústrias de confecção do vestuário de Pato Branco. Os dados obtidos demonstraram o estágio de desenvolvimento das empresas, englobando informações a respeito de gestão, modos de produção, design, matérias-primas utilizadas, quantidades e tipos de resíduos têxteis gerados. Esta pesquisa foi realizada entre os meses de dezembro de 2010 e fevereiro de 2011. Após a aplicação dos questionários, os dados foram analisados com o auxilio do software Questionare Pesquisador.

\section{Resultados e discussão}

\subsection{A indústria de confecção do vestuário de Pato Branco: aspectos de gestão}

Pato Branco possui cerca de 21 empresas no ramo de confecções do vestuário que atuavam em diferentes segmentos de mercado, tais como: Uniformes 
Escolares e Profissionais totalizando $43 \%$ das empresas, Moda Festa, Acessórios e Modinha com 12\% cada, Lingerie (8\%), Malharia Retilínea (8\%) e Jeanswear (5\%), como demonstram os dados presentes no gráfico 1 .

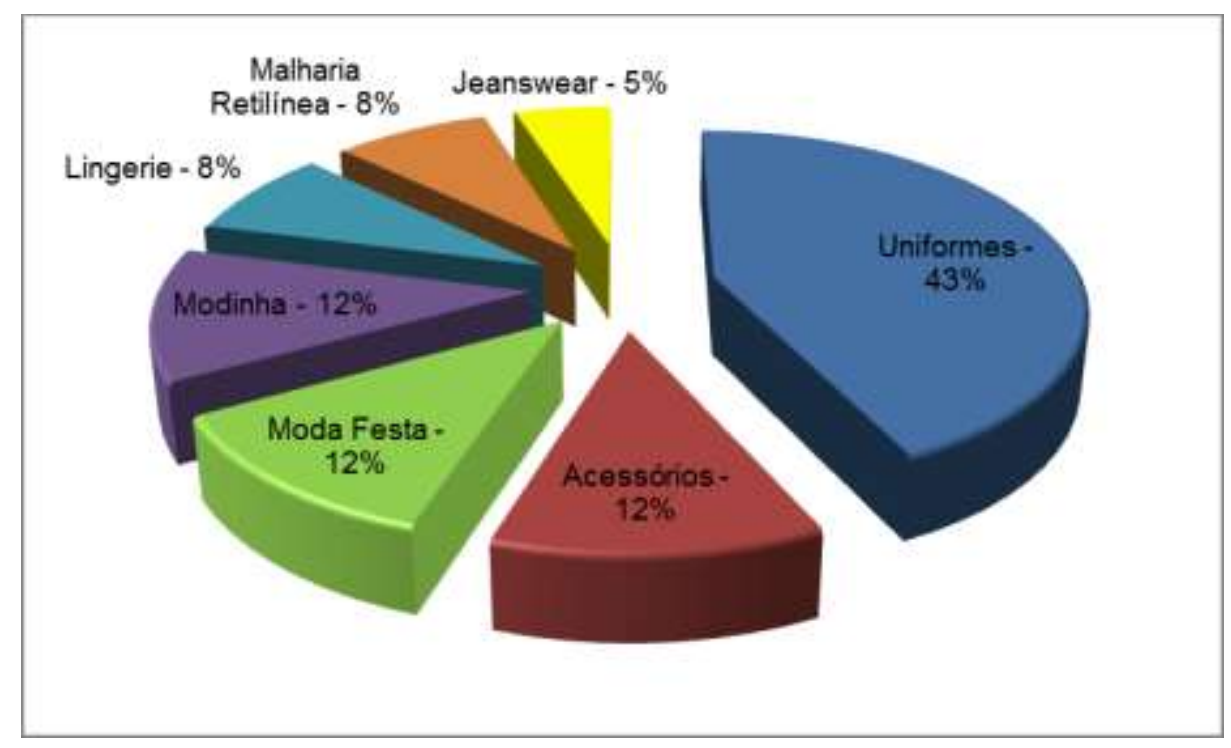

Gráfico 1: Segmentos de mercado trabalhados pelas indústrias de confecção do vestuário de Pato Branco (autores, 2012)

Quanto ao porte, as empresas podem ser classificadas em grandes, médias e pequenas segundo critérios universalmente aceitos, como o número de empregados, o volume de vendas, o valor dos ativos, o volume de depósitos etc (Chiavenato, 2005). Sob este aspecto, 95\% das empresas de confecção de Pato Branco enquadraram-se no porte micro, empregando no máximo 19 funcionários em suas atividades produtivas. Apenas $5 \%$ das empresas enquadraram-se em pequeno porte, empregando entre 20 e 29 funcionários. Nessas empresas, a forma de gestão adotada pela maioria é a familiar, totalizando $65 \%$, ao passo que $25 \%$ possuem gestão familiar associada à administradores contratados e $10 \%$ possuem gestão não familiar.

Em virtude tanto do tamanho, que na maioria das empresas é micro, bem como da gestão, familiar na maior parte delas, a distribuição de atividades nas empresas de Pato Branco é voltada a funcionários polivalentes, que acumulam várias funções, como por exemplo, o Planejamento e Controle da Produção - PCP, processo que em $80 \%$ das empresas é realizado por funcionário que exerce outras funções além desta. 
Outra característica observada durante a pesquisa foi a forma de divulgação dos produtos, geralmente realizada via rádio (26\%), tendo uma abrangência local e regional que incide diretamente nos principais centros onde são comercializados os produtos, onde destaca-se o próprio município com a porcentagem de $28 \%$, seguido pelo estado do Paraná $(20 \%)$ e Santa Catarina $(16 \%)$.

A política de comunicação dos produtos de moda pode variar entre publicidade, propaganda, promoção de vendas, merchandising e relações públicas. Sob este aspecto, outras formas de divulgação dos produtos eram realizadas no município, com destaque para a internet (15\%), catálogos (11\%) e revistas $(9 \%)$, demonstrando um alcance que ultrapassa as fronteiras do município, e que vai ao encontro de outros centros de comercialização dos produtos, como o estado do Rio Grande do Sul, que totaliza 6\% das vendas e outros estados do Brasil com o total de $10 \%$.

Nas atividades de vendas de moda, é essencial saber quem é o cliente, e quais são suas preferências de posse em relação ao produto, para que a venda seja efetuada com sucesso, e isso pressupõe uma negociação entre o produtor e o distribuidor, e entre este e o consumidor. (Cobra, 2007, p.124)

Dessa forma, as estratégias de comunicação a respeito do lançamento dos produtos de moda precisam estar em compatibilidade com a coleção e suas características. Por isso, além de comunicar através de imagens e publicações, é preciso capacitar os vendedores que terão contato direto com o consumidor. Esta interface entre vendedores e consumidores é intermediada pelas estratégias de vendas previamente definidas pelas empresas.

O arranjo físico onde são desempenhadas as atividades produtivas das empresas também foi abordado durante a pesquisa. O arranjo físico, também conhecido como layout é a maneira como são dispostos os elementos dentro da empresa tais como: homens, máquinas, equipamentos, instalações, corredores, etc (Corrêa, 2006). Para o autor, esta maneira deve sofrer constantes reavaliações para manter a eficácia e a eficiência das operações.

Neste quesito, $80 \%$ das empresas descreveram o arranjo físico (layout) de suas instalações como adequado ao desempenho das atividades requeridas, ao 
passo que $20 \%$ afirmaram possuir um espaço inadequado, tanto em relação à disposição dos maquinários quanto ao fluxo da produção. Dentro deste conjunto, em relação à organização da produção, 65\% utilizavam linhas convencionais enquanto $35 \%$ organizavam-se na forma de células.

Um layout adequado obedece a certos padrões de qualidade, sendo esta um item fundamental para as empresas que desejam permanecer no mercado por um longo período de tempo.

Para Corrêa (2006, p.25) "qualidade é um aspecto de desempenho de sistemas produtivos que se refere à oferta de produtos livres de defeitos e em conformidade com especificações técnicas." $\mathrm{Na}$ visão do autor, para que exista qualidade, é necessário o trabalho em grupo, envolvimento pessoal e participação de todas as pessoas em todos os níveis da organização, bem como a busca pela melhoria constante e contínua. Desse modo, dentro do contexto das empresas pesquisadas evidenciou-se que apenas $40 \%$ utilizavam programas de qualidade, tais como 5s e Qualidade Total. Isso demonstra um ponto onde há necessidade de melhorias, uma vez que o controle de qualidade deve iniciar antes do processo de fabricação, começando na escolha de bons fornecedores de matéria-prima, passando pela fase de desenvolvimento de produtos e operacionalização da produção, e culminando com a chegada deste no consumidor. O controle de qualidade deve ter caráter contínuo e integrado.

\subsection{O design e o desenvolvimento de produtos nas indústrias de confecção}

\section{do vestuário de Pato Branco}

A qualidade em uma empresa tem reflexos nos produtos fabricados, os quais passam por inúmeros processos até chegarem ao consumidor final. De acordo com Rech (2002) as características que orientam a qualidade do produto de moda começam na fase de criação, passando pelas etapas de confecção, acabamento e terminam na relação produto-consumidor. Isso demonstra que as fases pelas quais o produto passa dentro de uma empresa devem estar interligadas, para atenderem a requisitos de qualidade e satisfação dos clientes potenciais.

Dentre estas fases localiza-se o desenvolvimento de produtos, que, conforme Juran (1997) consiste em vários estágios sucessivos de um processo, 
partindo do conceito (ideia) até o cliente, com a finalidade de desenvolver produtos com características que atendam às necessidades destes.

Nesse sentido, foi pesquisada junto às empresas a existência de profissionais especializados desempenhando as funções relativas ao desenvolvimento de produto, sobretudo na fase de criação. Assim, conforme demonstrado no gráfico $2,80 \%$ das empresas afirmaram ter profissionais responsáveis pelo setor de desenvolvimento de produtos, contudo, estes profissionais geralmente não possuíam um nível de especialização necessário ao desempenho da função designer. Assim, quando analisado o nível de especialização desta função, os valores caíram para $31 \%$, demonstrando falta de esclarecimento a cerca do desempenho da função do designer de moda pelas empresas.

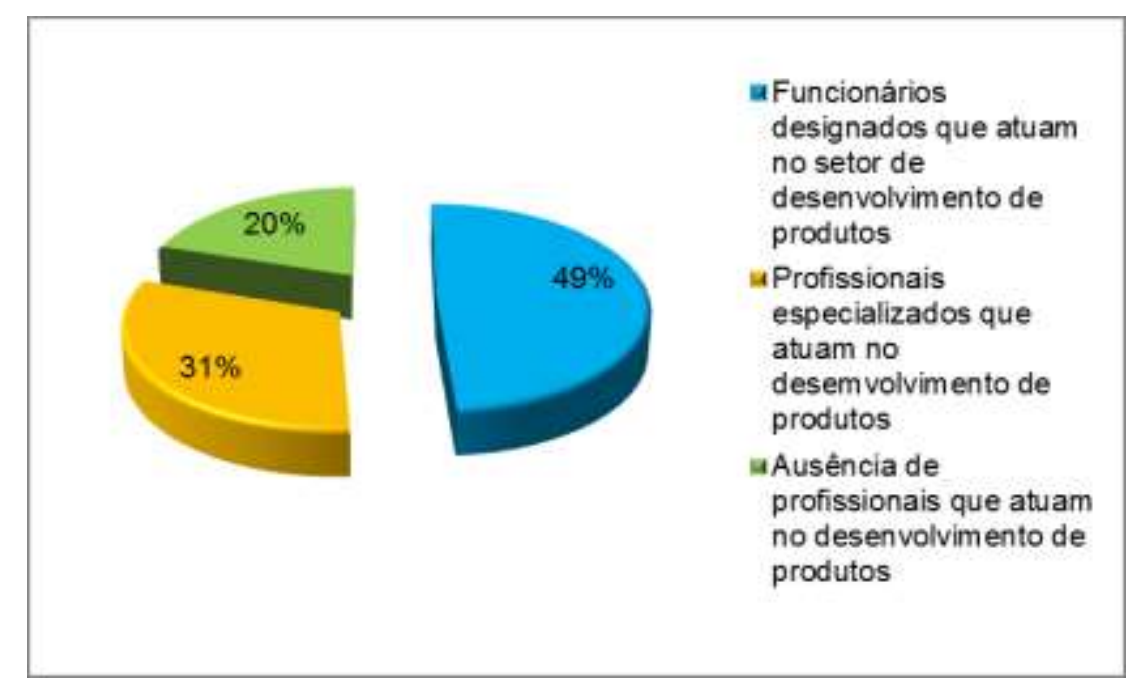

Gráfico 2: A atuação de profissionais no setor de desenvolvimento de produtos nas indústrias de confecção do vestuário de Pato Branco (Autores, 2012).

Produtos resultantes de projetos de design têm um melhor desempenho que aqueles desenvolvidos pelos métodos empíricos e são obtidos em um curto espaço de tempo, considerando conceito e cliente como os polos terminais do ciclo de desenvolvimento (Rech, 2002).

Não obstante, é fundamental que os responsáveis pela criação e desenvolvimento de produto tenham consciência de que o design aplicado ao produto determinará o seu sucesso comercial ou não. Contudo, o objetivo de projetar produtos é a satisfação das necessidades e expectativas do consumidor, sendo que o projeto de produtos inicia e termina no consumidor. Conforme Treptow 
(2005, p.49), "sempre que desenvolver um novo produto, seja ele um eletrodoméstico, um carro, ou uma coleção de moda, o designer deve levar em consideração a que tipo de consumidor ele se destina." Todo produto é sempre dirigido a um consumidor, e no produto de moda isso é ainda mais específico.

Pesquisas junto aos consumidores, aspecto de grande importância na indústria do vestuário foram abordadas durante 0 presente estudo. Ficou evidenciado que apenas $40 \%$ das empresas de Pato Branco realizavam este tipo de estudo prévio. As formas de pesquisa realizadas pelas empresas incluíam questionários e entrevistas direcionados aos representantes comerciais e às lojas onde as empresas disponibilizavam seus produtos para a venda.

Entrevista pode ser definida como um instrumento de coleta de dados que consiste em conversas orais, individuais ou em grupo com pessoas previamente selecionadas, cujo grau de pertinência, validade e confiabilidade é analisado-tendo como base os objetivos da pesquisa. (Gil, 2010)

Questionário consiste em uma técnica de investigação social composta por um conjunto de questões submetidas a pessoas a fim de obter informações específicas. (Gil, 2010)

Desse modo, o levantamento de dados demonstrou que $31 \%$ das empresas utilizavam entrevistas informais realizadas com os vendedores das lojas onde a empresa atuava. De modo semelhante, $31 \%$ das empresas aplicavam entrevistas informais aos representantes de vendas. Também eram utilizados questionários impressos, que consistiam em métodos mais formalizados direcionados tanto aos lojistas quanto aos representantes de vendas. Neste caso, $23 \%$ destinavam-se aos representantes de vendas e $15 \%$ aos lojistas. Tais resultados demonstram a necessidade de uma aproximação mais efetiva entre as empresas e seus clientes a fim de melhorar os processos produtivos, os produtos e consequentemente a conquista de mercado (gráfico 3). 


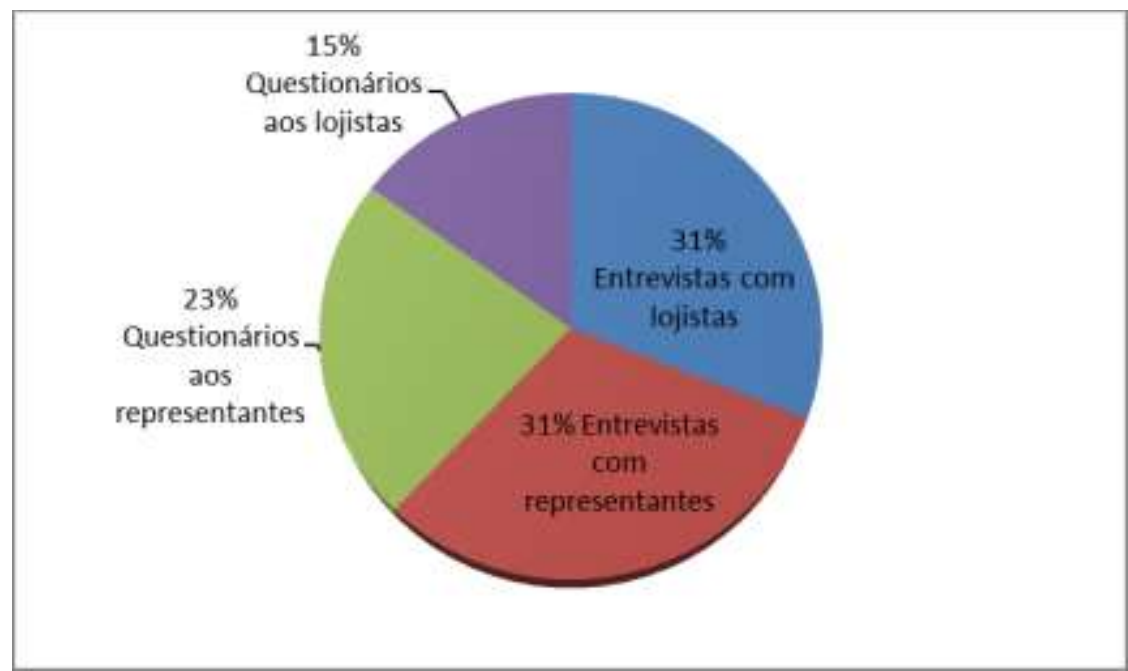

Gráfico 3: A realização de pesquisas com o público consumidor nas indústrias de confecção do vestuário de Pato Branco (Autores, 2012).

A visão sobre a pesquisa e a satisfação das necessidades dos consumidores corresponde às exigências de um projeto de produto, à medida que esse deve levar em conta inúmeros parâmetros, que podem ser específicos à empresa, correspondendo aos produtos, tecnologias e recursos, ou relativos ao mercado, que diz respeito à distribuição, à concorrência e os estilos de vida.

Outro tipo de pesquisa constantemente utilizado nas empresas do vestuário consiste na pesquisa de tendências de moda. De acordo com Treptow (2005), a pesquisa de tendência fundamenta-se na coleta de informações referentes ás tendências sazonais a fim de reunir elementos de estilo, amostras de materiais (tecidos e aviamentos), cores, e inspirações que sirvam de base para a criação de uma coleção de moda.

Sob este aspecto, evidenciou-se durante a pesquisa que $80 \%$ das empresas do município realizavam este tipo de estudo. Como todo bom analista, o designer de moda que utiliza a pesquisa de tendências, deve consultar diversas fontes de informações a fim de identificar elementos que definam a atmosfera geral e proporcionem segurança em sua proposta. Sobretudo o mesmo precisa decodificar, interpretar e adaptar essas informações ao seu ambiente e métodos de trabalho.

Dentro deste conjunto foram levantadas junto às empresas de Pato Branco, quais eram as fontes de informação consultadas durante a pesquisa de 
tendências de moda. Assim, constatou-se que a fonte mais utilizada eram os Sites Especializados que correspondiam a $35 \%$ das respostas.

A internet é uma ferramenta de pesquisa bastante utilizada por designers de moda, uma vez que a maioria das feiras internacionais, revistas especializadas, designers e marcas renomadas possuem sites próprios.

A consulta a Revistas de Moda Nacionais era utilizada por $25 \%$ das empresas pesquisadas. Visitas a Feiras do Setor também foram citadas, totalizando $22 \%$ das respostas. De modo menos expressivo foram assinaladas as Revistas de Moda Internacionais e os Birôs de Estilo com $9 \%$ cada.

Com efeito, a pesquisa deve fazer parte da rotina do designer, uma vez que o mesmo deve manter-se constantemente atualizado em relação ao contexto social, agregando características como a curiosidade e a percepção.

\subsection{Matérias-primas utilizadas nas indústrias de confecção do vestuário de Pato Branco}

As indústrias de confecção do vestuário do município trabalham em diferentes segmentos de mercado, com destaque para o segmento de Uniformes (43\%), seguidos pelos segmentos de Moda Festa, Acessórios e Modinha (12\% cada), segmentos de Lingerie (8\%), Malharia Retilínea (8\%) e Jeanswear (5\%). Esses dados demonstram uma diversificação de matérias-primas utilizadas e consequentemente de resíduos têxteis gerados. As empresas confeccionam diversos tipos de produtos, dentre eles calças, jaquetas, bermudas, camisetas, vestidos, shorts, blazers, saias, calcinhas e cuecas. Para a confecção destes produtos são necessários tecidos em diferentes ligamentos e composições de fibras como confirmou a pesquisa realizada.

Conforme Ribeiro (1984, p. 23) fibra têxtil é "a unidade de matéria, caracterizada por sua flexibilidade, finura e elevada proporção entre comprimento e finura, cujas propriedades a tornam capaz de ser transformada em fio". A origem das fibras pode ser natural, artificial ou sintética. Desse modo, as fibras naturais são formadas por macromoléculas lineares fornecidas ao homem pela natureza. As mesmas podem ser oriundas do reino animal, como a lã e seda; vegetal, como o algodão, linho; ou mineral como o amianto. As fibras artificiais utilizam matéria-prima 
natural, porém, necessitam passar por processos químicos para adquirirem características têxteis. São exemplos de fibras artificiais a viscose, modal, fibra de bambu, lyocell, cupro, entre outras. As fibras sintéticas são obtidas através da síntese de macromoléculas que são transformadas em filamentos, como é o caso do poliéster, poliamida, acrílico, elastano (Ribeiro, 1984).

Todas as fibras apresentam características boas, regulares e pobres, desse modo, quando surge a necessidade de fios ou tecidos que apresentem propriedades não encontradas numa única fibra, fazem-se as necessárias combinações, de modo que as propriedades desejadas sejam adquiridas, bem como as propriedades indesejadas sejam minimizadas.

Conforme Ribeiro (1984), as misturas de fibras são feitas por diversas razões, como para criar efeitos de cor sobre o tecido, melhorar a eficiência da fiação, da tecelagem e do acabamento, por razões econômicas, para obter melhor textura e aparência, bem como para obter maior desempenho em relação à durabilidade.

Sob esta perspectiva, nas empresas de Pato Branco as misturas entre fibras são utilizadas, prevalecendo em $48 \%$ a mistura entre fibras naturais e sintéticas, ao passo que as misturas entre naturais e artificiais e artificiais e sintéticas totalizam $52 \%$, sendo $26 \%$ correspondente à cada uma das misturas citadas conforme demonstrado no gráfico 4.

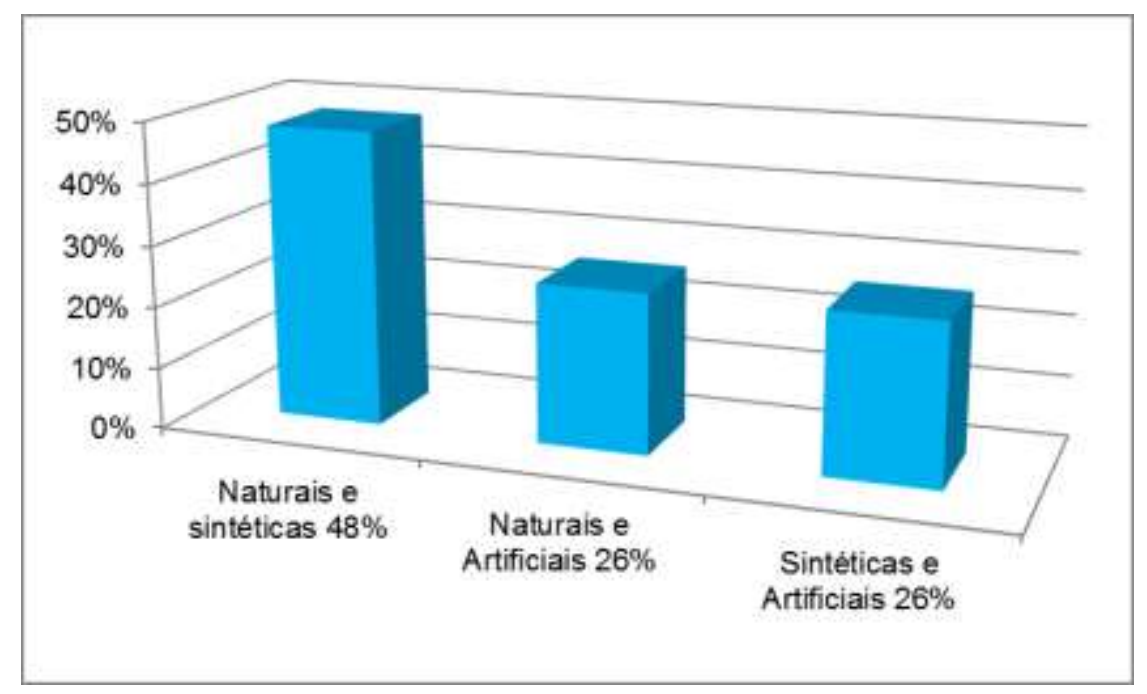

Gráfico 4: Principais misturas de fibras utilizadas pelas indústrias de confecção do vestuário de Pato Branco (Autores, 2012) 
Para Jones (2005), a adequação de um tecido para a criação de moda provém de uma combinação de fios, construção, peso, textura, cor, toque e estampa e também de fatores adicionais como ser quente, resistente a manchas ou fácil de lavar. O designer deve ter uma expectativa razoável de como o tecido vai se comportar, ou seja, não se pode forçar um tecido a assumir forma ou estilos incompatíveis com suas características práticas e visuais.

Em relação aos tecidos utilizados pelas confecções o consumo de tecidos malhas era $10 \%$ superior em comparação ao consumo de tecidos planos.

As malhas caracterizam-se pela formação de laços que se interpenetram e se apóiam lateral e verticalmente, provenientes de um ou mais fios (Treptow, 2005). Em função do tipo de entrelaçamento por laçadas, possuem maior elasticidade na largura e comprimento se comparadas aos tecidos planos, evidenciando conforto e versatilidade, propriedades que as tornam bastante difundidas em diversos segmentos de vestuário.

Dentro deste conjunto, os tecidos de malha mais citados durante a pesquisa foram: Viscolycra $-12 \%$, Meia-malha $-11 \%$, Ribana $-11 \%$, Moletom 10\%, Helanca - 10\%, Piquet - 9\%, Cotton - 5\%, Viscocrepe - 4\%, Liganete - 4\%, Moletinho $-4 \%$, Suplex $-4 \%$, Plush $-3 \%$, Jersey $-3 \%$, Tricô - $2 \%$, Gorgurão $-1 \%$ (Outros $-7 \%)^{2}$.

As malhas possuem construção que proporciona conforto e versatilidade, características obtidas pelos tecidos planos através da inserção de fibras elastoméricas como o elastano e poliuretano. Contudo, a maior utilização de tecidos de malha no município de Pato Branco se deve ao fato de que a maioria das empresas trabalha com uniformes, grande parte com uniformes escolares, responsáveis por utilizar tradicionalmente tecidos de malha em sua confecção. Somam-se a isso, outros segmentos que utilizam tecidos de malha, como o de lingeries, modinha, malharia retilínea, e moda festa que atualmente faz uso deste tipo de tecido, apesar de utilizar tecidos planos na maior parte das peças do vestuário.

Os tecidos planos são aqueles resultantes do entrelaçamento de duas camadas perpendiculares de fios (Ribeiro, 1984). 
Segundo Treptow (2005), os tecidos planos possuem estabilidade na largura e no comprimento, boa resistência, sendo usados para diversos fins além do vestuário, tais como decoração, embalagens e esportes.

Logo, os tecidos planos mais utilizados nas confecções de Pato Branco são: Brim - 13\%, Oxford-11\%, Piquet-11\%, Tactel - 9\%, Tricoline - 8\%, Tafetá $7 \%$, Mousseline $-6 \%$, Crepe $-4 \%$, Jeans $-3 \%$, Gabardine $-3 \%$, Popeline $-3 \%$, Linho - 3\%, Risca de giz - 3\%, Cambraia - 1\% (Outros -15\%).

Outro aspecto analisado durante a pesquisa foi a utilização de matériasprimas ecológicas. Constatou-se que $35 \%$ das empresas utilizavam esse tipo de material, como tecidos com fibra de bambu e lyocell, enquanto que em $65 \%$ das empresas as matérias-primas ecológicas não eram utilizadas.

Dentre as restrições para se trabalhar com este tipo de fibra, foram mencionadas a falta de interesse pelo publico consumidor (35\%), custo $(27 \%)$, fornecedores $(23 \%)$. Aspectos como caimento, qualidade e pouca variedade das matérias-primas também foram evidenciados (15\%).

\subsection{As indústrias de confecção do vestuário de Pato Branco e a geração de resíduos têxteis}

As fibras ecologicamente corretas e naturais possuem alto índice de biodegradabilidade quando comparados às fibras artificiais e sintéticas, pois a decomposição destas pode levar centenas de anos, além de utilizarem como matéria-prima recursos não renováveis.

Assim, durante a pesquisa realizada se fez necessário um levantamento a respeito da produção mensal das empresas, bem como do consumo de matériaprima e geração de resíduos têxteis.

Com uma produção mensal variando entre 130 e 26000 peças, constatouse que $41 \%$ das empresas produziam até 1000 peças ao mês, $29 \%$ produziam até 2000 peças, $23 \%$ produziam de 3000 a 8000 peças e $7 \%$ produziam acima de 10000 peças, totalizando a quantidade de 62.830 peças produzidas ao mês, quando somados os valores de todas as empresas do município. Para a produção destas peças eram gastos $2.150 \mathrm{Kg}$ de malha e $5.500 \mathrm{~m}$ de tecido plano, gerando 
aproximadamente $1425 \mathrm{~kg}$ de resíduos têxteis ao mês. Dentro deste contexto, 62\% das empresas produzem até $50 \mathrm{~kg}$ ao mês, $19 \%$ produzem entre 50 e $100 \mathrm{Kg}$, e 19\% produzem acima de $100 \mathrm{~kg}$ de resíduos ao mês, conforme pode ser visualizado no gráfico 5 .

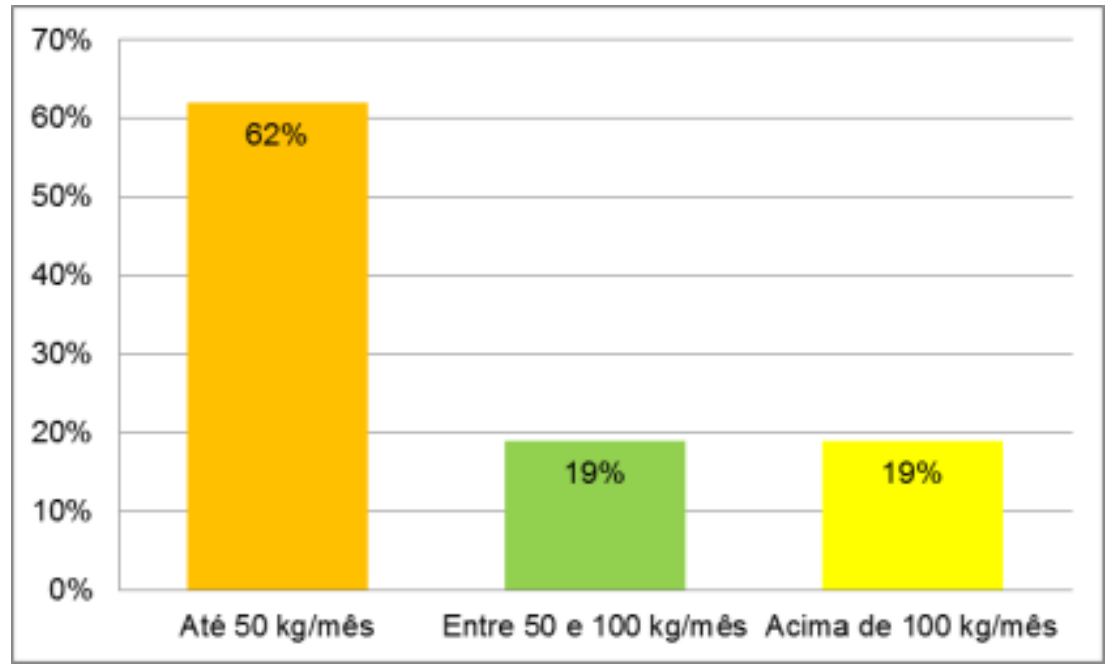

Gráfico 5: Geração de resíduos têxteis nas indústrias de confecção do vestuário de Pato Branco (Autores, 2012)

As empresas do segmento de uniformes, que representaram o maior montante da produção (43\%) eram as responsáveis por gerar maiores quantidades de resíduos, sendo estes em sua maioria formados por tecidos de malha. Apesar de haver uma discrepância em relação ao volume de produção das empresas devido à forma de segmentação das mesmas, observa-se que há uma geração de resíduos contínua e que tende ao crescimento em virtude do aumento da população que forma os mercados. Já o segmento moda festa, que caracteriza a porcentagem de $12 \%$ no município, apresentou um volume de produção relativamente menor, porém, os resíduos gerados possuem dimensões físicas maiores. Por outro lado, o município de Pato Branco, vem se destacando por concentrar instituições de ensino superior de abrangência regional, o que caracteriza um aumento no número de eventos sociais como formaturas, evidenciando o crescimento deste segmento de mercado no município que traz consigo, uma maior geração de resíduos têxteis.

Grande parte dos resíduos são gerados devido a problemas relacionados à falta de planejamento e qualidade nas etapas de modelagem, encaixe e corte.

A modelagem é a etapa da construção dos moldes para a confecção das peças. Por meio dos moldes são realizados o encaixe e corte do tecido e 
posteriormente a costura. Após os moldes prontos é efetuada a operação de encaixe, que consiste em distribuir os moldes no tecido, de forma econômica e respeitando informações técnicas dos tecidos.

Dentro desta perspectiva, uma das questões direcionadas às empresas procurou levantar se os serviços de encaixe e corte eram realizados por profissionais especializados. A pesquisa demonstrou que, em $75 \%$ das empresas haviam profissionais especializados trabalhando nestas operações, o que representa diminuição de desperdício de matéria-prima neste setor.

Também foi abordada a realização de estudos prévios para evitar o desperdício de tecidos durante as operações de encaixe e corte. Logo, constatou-se que $55 \%$ das empresas faziam uso de estudos como: planejamento de encaixe dos moldes (46\%), análise de modelagem e planejamento de encaixe (36\%) e reutilização de tecidos para a confecção de peças menores (9\%) (gráfico 6).

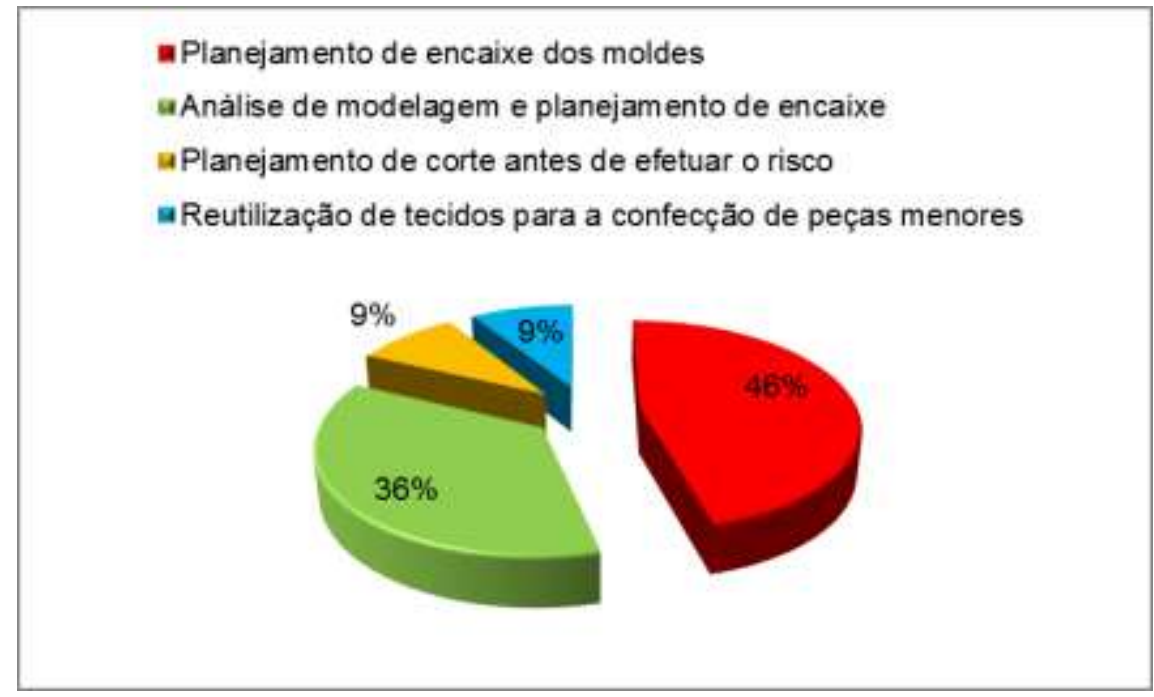

Gráfico 6: Realização de estudos prévios para evitar o desperdício de teciddo nas indústrias de confecção do vestuário de Pato Branco (Autores, 2012)

O encaixe pode ser realizado de três maneiras: disposição dos moldes diretamente sobre a folha de risco, estudo por meio de miniaturas confeccionadas por pantógrafo, e pelo sistema CAD/CAM.

O sistema CAD/CAM apresenta as maiores vantagens, economizando tempo e matéria-prima. Este sistema oferece ferramentas de encaixe automático, informando, ao término do encaixe, o consumo total de tecido, o consumo médio por 
peça e o índice de aproveitamento. Em razão disso, o sistema CAD/CAM agiliza o processo de encaixe risco e corte, economizando tempo e dinheiro (Treptow, 2005).

Sob esta perspectiva, foi pesquisado junto às empresas, se as mesmas utilizavam algum tipo de software específico para a área do vestuário, logo, constatou-se que apenas $10 \%$ das empresas do município possuíam este tipo de programa. A utilização de softwares nestes setores diminui o desperdício de tecidos e, consequentemente a geração de resíduos têxteis. Entretanto, o emprego de profissionais especializados nestes setores também reduz o desperdício, pois os mesmos devem posicionar os moldes diretamente sobre o tecido, verificando a melhor forma de aproveitamento, apesar disso, o fator tempo é uma desvantagem em relação ao sistema computadorizado.

Os resíduos têxteis provenientes do corte dos moldes nos tecidos não são os únicos tipos de resíduos gerados pelas empresas de confecção. Somam-se aos resíduos têxteis os efluentes têxteis originados nas atividades de estamparia e tingimento. Estas atividades representam grandes danos ambientais quando despejadas diretamente na natureza sem um tratamento adequado.

De acordo com Lee (2009), os corantes modernos são produzidos a partir de petroquímicos, um recurso não renovável, que os torna insustentáveis, além de provocar danos à saúde humana e ao meio ambiente.

A utilização da água é outro aspecto preocupante, "para tingir uma camiseta de 200 g são usados entre 16 e 20 litros de água" (Lee, 2009, p.88). Conforme afirmam Braungart e McDonough (apud Lee, 2009), cerca de metade dos problemas de desperdício de água no mundo estão ligados à produção de roupas e tecidos. Processos ligados aos beneficiamentos, como o alvejamento $e$ acabamentos químicos que conferem certas propriedades aos tecidos, também oferecem riscos à saúde humana e ao meio ambiente. Associam-se a estes dados, os processos de estampagem que utilizam corantes, espessantes, além de outros produtos químicos.

Conforme as informações expostas anteriormente, foram levantadas junto às empresas pesquisadas questões referentes aos processos de estamparia e tingimento. Assim, observou-se que $40 \%$ das empresas utilizavam serviços 
terceirizados de estamparia, ao passo que 30\% possuíam em sua sede setor de estamparia ou lavanderia próprios. Isso demonstra, no caso do serviço terceirizado, uma transferência de responsabilidades ambientais para com a empresa contratada, que deve arcar com programas de tratamento de efluentes. No caso das empresas que possuíam estes setores, é gerada uma expectativa em torno do tratamento dado aos efluentes gerados. Contudo, o maior objeto de estudo desta pesquisa, consiste nos resíduos têxteis, abordados na sequência.

Como foi visto anteriormente, as empresas utilizavam matérias-primas naturais, artificiais e sintéticas, que resultavam em produtos com diferentes composições têxteis. A estrutura têxtil mais utilizada foi a malha, amplamente empregada no segmento de uniformes. De modo semelhante, a fibra de algodão convencional, obteve destaque entre as principais fibras trabalhadas pelas empresas do município. Associa-se a esses dados, a utilização de fibras ecologicamente em escala reduzida, o que traz á tona problemas referentes à decomposição dos resíduos têxteis gerados pelos processos produtivos.

Os resíduos têxteis, quando descartados em locais inapropriados, se decompõe muito lentamente, ocasionando a contaminação da superfície e das fontes de água, além de contribuir com o efeito estufa, devido á presença de gás metano na composição dos resíduos têxteis em decomposição. Essas evidências também agravam a incidência de problemas de saúde nas populações que vivem próximas aos lixões.

Desse modo, o destino dos resíduos têxteis produzidos nas confecções também fez parte da presente pesquisa. Assim, verificou-se que em $72 \%$ das confecções os resíduos têxteis eram doados a entidades como APAE ${ }^{1}$, Clube de Mães, projetos da Prefeitura Municipal e particulares. De modo semelhante, $8 \%$ das empresas elaboravam novos produtos a partir do reaproveitamento dos resíduos, ao passo que $4 \%$ das empresas vendiam os resíduos têxteis e $4 \%$ utilizam serviços de coleta especializada. Entretanto, em 12\% das empresas, os resíduos eram desprezados em lixos comuns. As doações de material remanescente do processo produtivo das confecções para entidades de cunho social é um procedimento amparado por organizações da sociedade civil, também preocupadas com a correta destinação de resíduos têxteis e que visam o reaproveitamento destes. Contudo, o 
monitoramento constante destes resíduos deve ser realizado, a fim de que os receptores façam um bom uso destes, evitando o possível descarte em locais inadequados.

\section{Considerações finais}

A indústria de confecção do vestuário de Pato Branco é constituída por micro empresas que atuam em vários segmentos de mercado apresentando uma inclinação para o setor de uniformes escolares e profissionais. A grande maioria das empresas possui gestão familiar, bem como é comum a existência de funcionários polivalentes, que acumulam várias funções neste setor produtivo. Atualmente, muito se comenta a respeito das competências e habilidades necessárias para atuar em setores específicos da indústria do vestuário, isso se percebe com o aumento considerável de cursos voltados à formação dos diferentes profissionais que atuam junto a este setor.

A profissionalização do setor se reflete diretamente na qualidade final dos produtos gerados e dos processos requeridos para tal fim. Dentro deste quadro, destaca-se a função do designer de moda, principal responsável pelo desenvolvimento das coleções do vestuário. Este profissional deve ter capacidade para converter informações, tais como dados de vendas de coleções anteriores, produtos concorrentes, novas tecnologias relacionadas a matérias-primas e métodos de produção e tendências de moda em produtos tangíveis passíveis de consumo. Para tanto, a formação acadêmica é imprescindível, pois não há espaço para atuar de modo amador em um mercado de rápidas transformações como o da moda.

Neste quesito, a indústria do vestuário de Pato Branco demonstra fragilidade, pois em sua grande maioria os profissionais que desempenham as funções relacionadas ao setor de desenvolvimento de produtos não possuem formação acadêmica na área. Estudos demonstram que a atuação de um profissional capacitado neste setor, além de otimizar a qualidade final dos produtos gerados também impacta em um melhor aproveitamento das matérias-primas utilizadas, tudo isso trabalhando em conjunto com os profissionais de modelagem e corte, setores relacionados à questão de eliminação de desperdícios de materiais têxteis. 
Soma-se a isso a ideia defendida por Rech (2002) de que produtos resultantes de projetos de design possuem um melhor desempenho do que aqueles desenvolvidos por métodos empíricos na medida em que consideram os clientes como início e fim do processo.

Um dos objetivos do processo de planejamento de produtos consiste na satisfação das necessidades e expectativas do consumidor. Nestes parâmetros, as pesquisas junto aos consumidores são essenciais. Sob este aspecto, a presente investigação evidenciou outra fragilidade relacionada às empresas do município em questão, na medida em que nestas, esta categoria de pesquisa está presente somente em $40 \%$ do universo pesquisado.

Outras pesquisas também são relevantes dentro deste universo, dentre elas, a pesquisa de tendências de moda. Assim, evidenciou-se um aspecto positivo em relação à atuação dessas empresas, pois, em $80 \%$ delas são realizados este tipo de estudo que consequentemente contribuem para a contemporaneidade das formas e materiais utilizados nos produtos.

Com efeito, a pesquisa deve fazer parte da rotina do designer, uma vez que este deve manter-se constantemente atualizado em relação aos inúmeros aspectos que envolvem o desenvolvimento de um produto, desde uma tendência de moda, passando por novos materiais, tecnologias e processos de produção.

De fundamental importância neste processo consistem as matériasprimas a serem utilizadas. Além de serem um dos principais itens que compõe o custo final de um produto, sua utilização também está relacionada aos impactos ambientais gerados por este tipo de indústria. (Treptow, 2005).

Neste sentido, a pesquisa evidenciou a utilização tanto de fibras naturais, artificiais e sintéticas, puras ou em composições mistas.

Do ponto de vista da biodegradabilidade das fibras, as de origem natural e artificial são melhor degradas quando expostas ao meio ambiente. Em contrapartida, fibras sintéticas apresentam maiores dificuldades quanto à degradação. $O$ que pode contribuir para uma melhoria neste quadro é a utilização de matérias-primas ecológicas. Dentro do universo pesquisado, estas são utilizadas na totalidade de $35 \%$, sendo representadas por tecidos com fibra de bambu e lyocell. Algumas 
restrições para se trabalhar com este tipo de fibra, foram mencionadas, tais como a falta de interesse pelo publico consumidor (35\%), custo $(27 \%)$, fornecedores $(23 \%)$.

Porém, independente da origem das fibras que compõe os tecidos estas se transformarão em resíduos no final das operações de produção. Desse modo, a pesquisa demonstrou a geração mensal de $1425 \mathrm{~kg}$ de resíduos têxteis oriundos das empresas de Pato Branco. As empresas do segmento de uniformes, que representaram o maior montante da produção (43\%) eram as responsáveis por gerar maiores quantidades de resíduos, sendo estes em sua maioria formados por tecidos de malha.

Grande parte dos resíduos são gerados devido a problemas relacionados às etapas de modelagem, encaixe e corte. Entretanto, em $75 \%$ das empresas essas funções eram exercidas por profissionais especializados, o que minimiza 0 desperdício de matéria-prima. Outro fator que diminui o desperdício de matériaprima é a realização de estudos prévios como análise da modelagem, planejamento de encaixe dos moldes e reutilização de tecidos para a confecção de peças menores. Neste sentido, 55\% das empresas afirmou utilizar algum desses métodos, evidenciando uma preocupação que tanto pode ser de caráter financeiro como ambiental.

Enquanto problema ambiental, os resíduos têxteis, quando descartados em locais inapropriados, podem ocasionar a contaminação da superfície, das fontes de água, além de contribuir com o efeito estufa e aumentar a incidência de problemas de saúde. Neste sentido, no que tange à destinação dos resíduos têxteis foi observado que a maioria das empresas faz doações dos mesmos, minimizando o acúmulo destes em lixões e aterros sanitários, o que do ponto de vista social e ambiental mostra-se de grande relevância. De modo semelhante, alternativas como a elaboração de novos produtos, venda dos resíduos têxteis e utilização de serviços de coleta especializada também foram observados.

As doações de material remanescente do processo produtivo das confecções para entidades de cunho social é um procedimento amparado por organizações da sociedade civil. Contudo, o monitoramento destes resíduos deve ser realizado, evitando seu possível descarte em locais inadequados. 
Notas:
${ }^{1}$ Associação de Pais e Amigos dos Excepcionais.

\section{Glossário:}

Brim: sarja de algodão de fios brancos e coloridos, originária da cidade francesa Nîmes.

Cambraia: tecido fino, leve e transparente produzido em algodão ou linho.

Crepe: tecido que se caracteriza por superfícies crespas ou enrugadas.

Gabardine: tecido de superfície homogênea com efeito de estrias finas diagonais em relevo, específico para a confecção de ternos, casacos e calças.

Gorgurão: tecido encorpado, normalmente em seda, lã ou algodão, com efeito de nervuras no sentido da trama.

Helanca®: ao longo do tempo a expressão também passou a denominar o tecido que contém este fio; fio sintético.

Jersey: tecido de malha, macio e elástico, usado normalmente na confecção de roupas femininas.

Liganete: malha de jersey bem fina, fria, geralmente usada na confecção de saiotes, combinações e blusinhas de verão.

Meia-malha: estrutura mais simples de uma malha.

Moletom: tecido de algodão grosso com uma face lanosa, a qual fica junto à pele.

Mousseline: tecido fino, leve e liso, geralmente em algodão, seda ou lã.

Oxford: tecido produzido utilizando-se fios mais finos no urdume, geralmente de uma cor, e fios mais grossos na trama, normalmente brancos.

Piquet: tecido com características diversas, que apresenta no lado comercial (face), desenhos com várias formas e em alto-relevo. No lado avesso apresenta tramas grossas, que provocam os relevos.

Plush: tecido de malha em algodão com pelos semelhantes aos do veludo.

Popeline: o nome vem do tecido papalino, que era feito na cidade papal Avignon, França, e usado para vestes clericais.

Ribana: conhecida como malha sanfonada, usada em punhos, cós e golas de peças em malha.

Risca de giz: risca branca sobre fundo escuro, em geral marinho, cinza ou preto, que se repete em determinados intervalos no sentido do urdume criando um padrão formal, muito utilizado em ternos de lã.

Suplex: tecido que une a maciez das malhas de algodão à resistência do nylon, tem bom caimento, secagem rápida e é muito usado em peças esportivas.

Tactel: sua composição é $100 \%$ poliamida, utilizado em roupas esportivas, tem leveza no caimento. Tricoline: tecido de armação tafetá, produzido com fios finos $100 \%$ em algodão.

\section{Referências}

CHATAIGNIER, G. Fio a fio: tecidos, moda e linguagem. São Paulo: Estação das letras e Cores, 2009.

CHIAVENATO, I. Empreendedorismo: Dando asas ao espírito empreendedor. São Paulo: Saraiva, 2005.

COBRA, M. Marketing \& moda. São Paulo: Editora Senac: Cobra Editora \& Marketing, 2007.

CORRÊA, H. L. Administração de Produção e Operação: manufatura e serviços - uma visão estratégica. 2. ed. São Paulo: Atlas, 2006.

CURY, A. Organização e métodos: Uma visão holística. $6^{\mathrm{a}}$ ed. São Paulo, SP: Atlas S.A., 1995.

FURTADO, M. B. Síntese da economia brasileira. 5. ed. Rio de Janeiro: Livros Técnicos e Científicos, 1988. 
INSTITUTO PARANAENSE DE DESENVOLVIMENTO ECONÔMICO E SOCIAL (IPARDES). Secretaria de Estado do Planejamento e Coordenação Geral. Caderno Estatístico Município de Pato Branco. Curitiba: IPARDES, 2011. Disponível em: < http://www.ipardes.gov.br/cadernos/Montapdf.php?Municipio=85500\&btOk=0k> Acesso em 29/07/2011.

INSTITUTO PARANAENSE DE DESENVOLVIMENTO ECONÔMICO E SOCIAL (IPARDES). Secretaria de Estado do Planejamento e Coordenação Geral. Identificação e Mapeamento das Aglomerações produtivas do Paraná: Atualização 2008. Curitiba: IPARDES, 2009. Disponível em: $<$ http://www.ipardes.pr.gov.br/biblioteca/docs/mapeamento_aglomeracoes_produtiva s.pdf> Acesso em 26/10/2011.

JONES, S. J. Fashion design: manual do estilista. São Paulo: Cosac \& Naify, 2005.

JURAN, J.M. A Qualidade desde o Projeto - os novos passos para o planejamento da qualidade em produtos e serviços. São Paulo: Pioneira, 1997.

LEE, M. Eco chic: o guia de moda ética para a consumidora consciente. São Paulo: Larousse do Brasil, 2009.

PEZZOLO, D. B. Tecidos: história, tramas, tipos e usos. 2. ed. São Paulo: Senac, 2009 .

RECH, S. R. Moda: por um fio de qualidade. Florianópolis: UDESC, 2002.

RIBEIRO, L. G. Introdução a tecnologia têxtil I. Rio de Janeiro: Senai/Cetiqt, 1984.

SAQUET, D. B. A expansão da indústria de confecções no Sudoeste do Paraná. Geosul: Florianópolis, v. 23, n. 46, p 55-78, jul./dez. 2008.

SINVESPAR. Diagnóstico das indústrias do vestuário do Paraná. 2008. Disponível em: < http://www.sinvespar.com.br/conteudo/diagnostico_pr.asp >. Acesso em 15/04/2010.

SINVESPAR. APL moda masculina sudoeste do Paraná: plano de desenvolvimento: o arranjo produtivo local de moda masculina do sudoeste do Paraná. 2006. Disponível em: <http://www.sinvespar.com.br>. Acesso em 15/04/2010.

SLACK, N. et al. Administração da Produção. São Paulo: Atlas, 1997.

TREPTOW, D. Inventando moda: planejamento de coleção. Brusque: Dóris Treptow, 2005. 